\title{
AVALIAÇÃO DA REMOÇÃO DE ETANOL DE SOLUÇÕES HIDROALCOÓLICAS POR STRIPPING UTILIZANDO NITROGÊNIO COMO GÁS DE ARRASTE
}

\author{
C. E. M. PINTO1 ${ }^{\text {, J. L. S. SONEGO², D. A. } \text { LEMOS}^{2} \text { e A. C. BADINO² }}$ \\ ${ }^{1}$ Universidade Federal de São Carlos, Departamento de Engenharia Química \\ 2 Programa de Pós-Graduação em Engenharia Química, Universidade Federal de São Carlos
}

E-mail para contato: carlos.martinspinto@gmail.com

\begin{abstract}
RESUMO - Neste trabalho, foi estudada a extração de etanol de soluções hidroalcoólicas empregando de $\mathrm{N}_{2}$ como gás de arraste. Para avaliar as influências das variáveis de processo no arraste foi realizado um planejamento experimental do tipo delineamento composto central rotacional (DCCR), variando a vazão específica do gás de arraste, a temperatura da solução hidroalcoólica e a concentração inicial de etanol. Como variáveis respostas foram analisados os fatores de arraste $\left(\mathrm{F}_{\mathrm{A}}\right)$ e de concentração $\left(\mathrm{F}_{\mathrm{C}}\right)$ de etanol. $\mathrm{O}$ emprego de nitrogênio como gás de arraste proporcionou a remoção de até $48,1 \%$ do etanol após seis horas de esgotamento, com vazão de 4 vvm a temperatura de $32^{\circ} \mathrm{C}$, com concentração inicial de etanol de 45 g. $\mathrm{L}^{-1}$. Ademais, verificou-se a vazão específica de gás como a variável mais influente na remoção de etanol das soluções hidroalcoólicas, sendo estatisticamente significativa nas duas respostas estudadas. Assim, o emprego de nitrogênio como gás de arraste mostrou-se promissor para remover parte do etanol presente em soluções hidroalcoólicas, podendo ser futuramente estudado durante o processo fermentativo.
\end{abstract}

\section{INTRODUÇÃO}

A demanda energética mundial cresce anualmente, logo há a necessidade de formas mais sustentáveis de produzi-la, a fim de reduzir os impactos ambientais e a dependência em relação aos combustíveis fósseis. Nas últimas décadas, o Brasil consolidou-se como um país de notável participação de fontes renováveis em sua matriz energética, especialmente na geração de energia elétrica e de biocombustíveis para automóveis (MOTA, 2011).

O etanol, principal biocombustível brasileiro, começou a ser misturado na gasolina a partir da década de 1930 e a ser utilizado como combustível para automóveis na década de 1970, impulsionado pelo programa Proálcool. Com o desenvolvimento dos motores bicombustíveis no começo da última década, a demanda por etanol aumentou rapidamente, acompanhado por seguidos recordes na safra de cana-de-açúcar.

No Brasil, o principal método de produção de etanol é a partir da fermentação anaeróbica do caldo da cana pela levedura Saccharomyces cerevisiae, sendo os principais 
produtos ATP (energia química para a levedura), etanol e gás carbônico. Durante o processo, em concentrações acima de $40 \mathrm{~g} / \mathrm{L}$, o etanol começa a inibir sua própria biossíntese e, quando a concentração atinge valores acima de 95 g.L $\mathrm{L}^{-1}$, a produção cessa. Para contornar esse problema, atualmente a fermentação é realizada em grandes dornas para que a produção temporal seja satisfatória, o que gera altos custos de investimentos. Em adição a isso, o gasto energético durante a destilação e o grande volume de vinhaça são dois grandes problemas relacionados com a produção de etanol (SONEGO et al., 2014).

Para atenuar este problema, durante o processo fermentativo é possível remover uma parte do etanol formado por stripping. A operação consiste em uma corrente de gás inerte e insolúvel injetada no meio, que forma bolhas que promovem a migração de parte da solução. A solução arrastada apresenta maior concentração do composto mais volátil do que a solução original, criando um gradiente favorável para a transferência de massa. O presente trabalho teve como objetivo avaliar a influência da vazão especifica de $\mathrm{N}_{2}$, da temperatura da solução e da concentração de etanol no arraste de etanol a partir de soluções hidroalcoólicas por borbulhamento de gás nitrogênio.

\section{MATERIAL E MÉTODOS}

Com a finalidade de avaliar quais variáveis apresentam maior influência no processo de esgotamento com nitrogênio, foi realizado um estudo do arraste de etanol a partir de soluções hidroalcoólicas, variando a vazão específica de alimentação de $\mathrm{N}_{2}(\Phi)$, a temperatura da solução $(\mathrm{T})$ e a concentração inicial de etanol $\left(\mathrm{C}_{\mathrm{E}}\right)$ na solução.

\subsection{Equipamento e Procedimento Experimental}

Para a realização dos experimentos, colocou-se a solução hidroalcoólica em um reator pneumático do tipo coluna de bolhas encamisado com volume útil de $5 \mathrm{~L}$ (BADINO et al., 2007), cuja temperatura foi controlada por um banho termostatizado e monitorada por um termômetro digital. Utilizou-se nitrogênio industrial armazenado em torpedo como gás de arraste, com vazão controlada por um fluxômetro de massa. A Figura 1 mostra o esquema do aparato experimental utilizado.

Figura 1 - Esquema representativo do aparato experimental

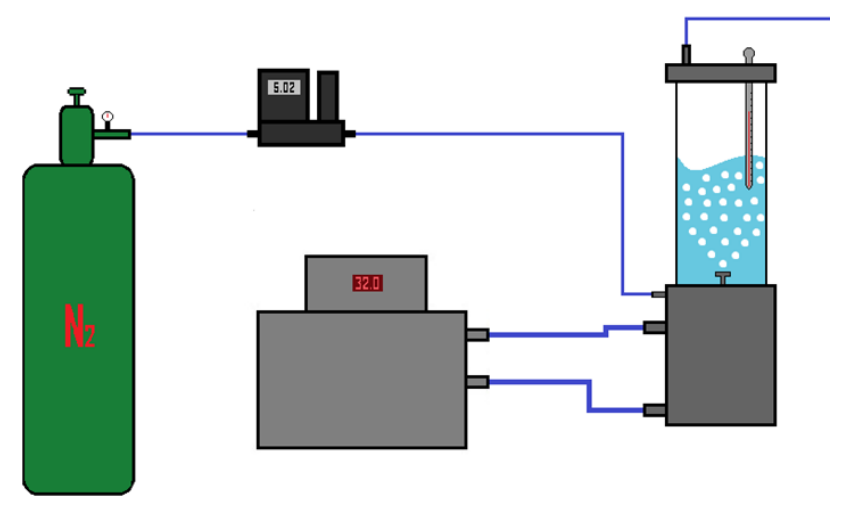

Para acompanhar o arraste de etanol das soluções hidroalcoólicas, amostras de 4,0 mL foram coletadas a cada $1 \mathrm{~h}$ por um período de $6 \mathrm{~h}$ de esgotamento, registrando-se também a 
variação do volume da solução entre cada medição, a partir da variação da altura da solução no biorreator, medida com um paquímetro.

\subsection{Estudo do arraste de etanol - Influências da vazão de $\mathbf{N}_{2}$, temperatura da solução e concentração inicial de etanol}

Para verificar as influências das variáveis no arraste de etanol (stripping), montou-se um planejamento experimental do tipo Delineamento Composto Central Rotacional (DCCR) com três repetições no ponto central, totalizando 17 experimentos (RODRIGUES e IEMMA, 2009). Na Tabela 1 são apresentados os valores numéricos das variáveis analisadas.

Tabela 1: Valores reais e codificados das variáveis independentes utilizadas nos experimentos com solução hidroalcoólica

\begin{tabular}{ccccccc}
\hline \multirow{2}{*}{ Variável } & \multirow{2}{*}{ Código } & \multicolumn{6}{c}{ Nível } \\
\cline { 3 - 7 } & & $-1,68$ & -1 & 0 & 1 & 1,68 \\
\hline Vazão do Gás $\boldsymbol{\Phi}(\mathrm{vvm})$ & $\mathrm{X}_{1}$ & 1,00 & 1,61 & 2,5 & 3,39 & 4,00 \\
Temperatura da Solução T $\left({ }^{\circ} \mathrm{C}\right)$ & $\mathrm{X}_{2}$ & 30,0 & 30,8 & 32,0 & 33,2 & 34,0 \\
Concentração de Etanol $\mathbf{C}_{\mathbf{E}}\left(\mathrm{g} \cdot \mathrm{L}^{-1}\right)$ & $\mathrm{X}_{3}$ & 30,0 & 36,1 & 45,0 & 53,9 & 60 \\
\hline
\end{tabular}

As respostas analisadas foram o fator de arraste $\left(\mathrm{F}_{\mathrm{A}}\right)$ e o fator de concentração $\left(\mathrm{F}_{\mathrm{C}}\right)$ (SONEGO et al., 2014, ESPERANÇA, 2011), descritas nas equações 1 e 2, respectivamente.

$$
\begin{aligned}
F_{A}= & \frac{C_{E 0} \cdot V_{0}-C_{E F} \cdot V_{F}}{C_{E 0} \cdot V_{0}} \cdot 100 \\
F_{C}= & \frac{\frac{C_{E 0} \cdot V_{0}-C_{E F} \cdot V_{F}}{V_{0}-V_{F}}}{C_{E 0}}
\end{aligned}
$$

onde $\mathrm{C}_{\mathrm{E} 0}$ é a concentração inicial de etanol $\left(\mathrm{g} . \mathrm{L}^{-1}\right), \mathrm{C}_{\mathrm{EF}}$ é a concentração final de etanol (g.L$\left.{ }^{1}\right), V_{0}$ é o volume inicial da solução (L) e $V_{F}$ é o volume final da solução (L).

\subsection{Determinação da Concentração de Etanol}

A concentração de etanol foi determinada empregando-se cromatografia liquida de alta eficiência (CLAE) em cromatógrafo equipado com detector de índice de refração (Waters). Foi empregada uma coluna Sugar-Pak I $(300 \times 6,5 \mathrm{~mm}, 10 \mu \mathrm{m}$, Waters $)$ operada a $80^{\circ} \mathrm{C}$ e água ultrapura como efluente, a uma vazão de $0,5 \mathrm{~mL} \cdot \mathrm{min}^{-1}$.

\section{RESULTADOS E DISCUSSÃO}

A partir dos dados de concentração de etanol e dos volumes inicial $\left(\mathrm{V}_{0}\right)$ e final $\left(\mathrm{V}_{\mathrm{F}}\right)$ da solução hidroalcoólica, determinou-se os valores das variáveis resposta do processo de arraste, de acordo com as equações 1 e 2 . Os valores apresentados e utilizados na análise estatística são referentes ao tempo final do processo de esgotamento (6 horas). Na Tabela 2 estão expostas a matriz do planejamento e os valores das duas respostas obtidas, os fatores de arraste $\left(\mathrm{F}_{\mathrm{A}}\right)$ e de concentração $\left(\mathrm{F}_{\mathrm{C}}\right)$. 
Tabela 2: Matriz do planejamento DCCR e valores numéricos das respostas

\begin{tabular}{cccccc}
\hline Ensaio & $\mathbf{X}_{\mathbf{1}}$ & $\mathbf{X}_{\mathbf{2}}$ & $\mathbf{X}_{\mathbf{3}}$ & $\mathbf{F}_{\mathbf{A}} \mathbf{( \% )}$ & $\mathbf{F}_{\mathbf{C}} \mathbf{( - )}$ \\
\hline 1 & 1 & 1 & 1 & 42,6 & 4,87 \\
2 & 1 & 1 & -1 & 38,4 & 5,02 \\
3 & 1 & -1 & 1 & 42,9 & 5,93 \\
4 & 1 & -1 & -1 & 38,2 & 6,04 \\
5 & -1 & 1 & 1 & 23,4 & 5,89 \\
6 & -1 & 1 & -1 & 21,3 & 8,79 \\
7 & -1 & -1 & 1 & 21,5 & 6,82 \\
8 & -1 & -1 & -1 & 18,8 & 6,79 \\
9 & 0 & 0 & 0 & 30,4 & 6,92 \\
10 & 0 & 0 & 0 & 31,6 & 6,38 \\
11 & 0 & 0 & 0 & 32,0 & 6,19 \\
12 & 0 & 0 & $-1,682$ & 29,7 & 5,09 \\
13 & 0 & 0 & 1,682 & 37,0 & 6,34 \\
14 & 0 & $-1,682$ & 0 & 32,4 & 6,30 \\
15 & 0 & 1,682 & 0 & 31,7 & 4,86 \\
16 & $-1,682$ & 0 & 0 & 15,0 & 5,39 \\
17 & 1,682 & 0 & 0 & 48,1 & 5,17 \\
\hline
\end{tabular}

A partir dos resultados da Tabela 2, verifica-se que os ensaios com as vazões de $\mathrm{N}_{2}$ mais altas obtiveram maiores os valores de fator de arraste, como pode ser visto nos ensaios 1 $\left(\mathrm{F}_{\mathrm{A}}=42,6 \%\right), 2\left(\mathrm{~F}_{\mathrm{A}}=38,4 \%\right), 3\left(\mathrm{~F}_{\mathrm{A}}=42,9 \%\right), 4\left(\mathrm{~F}_{\mathrm{A}}=38,2 \%\right)$ e $17\left(\mathrm{~F}_{\mathrm{A}}=48,1 \%\right)$. Os resultados para o fator de arraste indicam que os valores de $\mathrm{F}_{\mathrm{A}}$ se elevam com o aumento da vazão específica de $\mathrm{N}_{2}$ e da temperatura. Para os ensaios com vazões mais baixas, aumentos da temperatura e da concentração inicial de etanol também ocasionaram incrementos no valor de $\mathrm{F}_{\mathrm{A}}$, conforme pode ser observado nos ensaios $8\left(\mathrm{~F}_{\mathrm{A}}=18,8 \%\right)$ e $5\left(\mathrm{~F}_{\mathrm{A}}=23,4 \%\right)$. Sonego et al. (2014) ao estudar o arraste de etanol por $\mathrm{CO}_{2}$ também observaram um aumento no valor do fator de arraste quando a vazão específica de gás aumentou de $0,5 \mathrm{vvm}$ para 2,0 vvm e temperatura passou de $30{ }^{\circ} \mathrm{C}$ para $34{ }^{\circ} \mathrm{C}$. Ademais, verificou-se que aumentos na vazão específica para uma mesma condição de temperatura e concentração inicial de etanol levaram a uma redução no fator de concentração, conforme pode-se observar nos ensaios 6 e 2 onde o valor do $\mathrm{F}_{\mathrm{C}}$ passou de 8,79 para 5,02, respectivamente.

Com base nos valores das respostas obtidas nos ensaios referentes ao planejamento experimental (Tabela 2), foi possível construir os Diagramas de Pareto para os fatores de arraste $\left(\mathrm{F}_{\mathrm{A}}\right)$ e de concentração $\left(\mathrm{F}_{\mathrm{C}}\right)$, conforme mostrado na Figura 2. Para tal, adotou-se um intervalo de confiança de $90 \%$.

Figura 2 - Diagramas de Pareto para os fatores de arraste e de concentração 

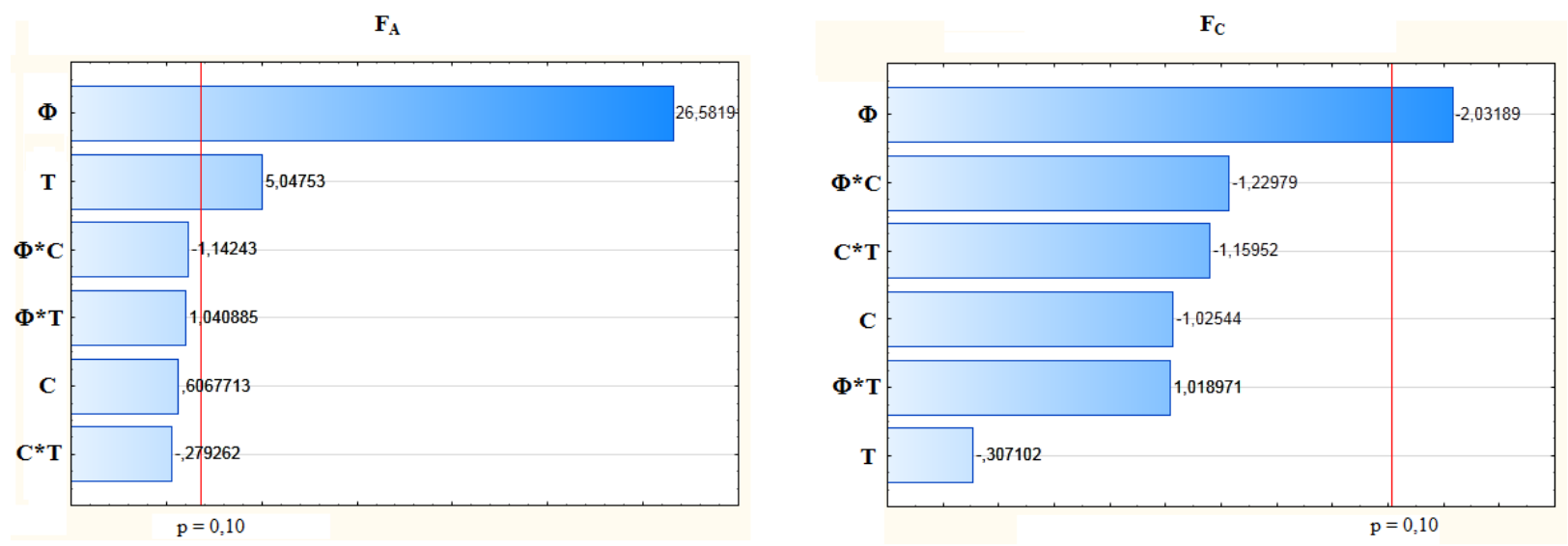

Analisando-se a Figura 2, é possível observar que a vazão específica $(\Phi)$ de nitrogênio foi a variável de maior influência no arraste de etanol, acarretando um efeito positivo sobre o fator de arraste. O resultado aponta que o aumento da vazão promove um maior arraste de etanol, devido à elevação da área de contato entre o gás e a solução. Entretanto, a vazão específica de gás teve um efeito negativo sobre o fator de concentração, uma vez que há dois tipos de arraste, o arraste termodinâmico (vaporização) e o arraste mecânico (sublação), sendo que o aumento da vazão favorece o segundo.

A temperatura denotou influência apenas sobre o fator de arraste. Com o aumento da temperatura da solução, as pressões de saturação do etanol e da água se elevam. Por ser mais volátil e apresentar menor tensão superficial, a vazão de vaporização do etanol é maior ocorrendo um aumento da fração de etanol na fase gasosa. Entretanto, como o intervalo da vazão estudado foi alto, o arraste mecânico do etanol foi mais expressivo, devido ao efeito da tensão superficial, mascarando os efeitos da temperatura sobre o arraste termodinâmico. Por fim, verificou-se que a concentração inicial da solução e as interações entre as variáveis respostas não foram estatisticamente significativas.

\section{CONCLUSÃO}

$\mathrm{O}$ fator de arraste $\left(\mathrm{F}_{\mathrm{A}}\right)$ mostrou-se fortemente influenciado pela vazão do gás, resultando em um efeito positivo no arraste de etanol, pois o aumento da vazão amplia a área de transferência de massa entre as fases (bolhas e a solução hidroalcoólica), contribuindo para o arraste de etanol. A temperatura também contribuiu de maneira significativa no fator de arraste com um efeito positivo, devido à elevação da pressão de saturação da fase líquida.

O fator de concentração foi influenciado pela vazão de gás de forma negativa, pois, com o favorecimento da sublação, ocorre o arraste de maior quantidade de água, gerando, assim, uma corrente de saída mais pobre em etanol.

O processo de stripping empregando $\mathrm{N}_{2}$ como gás de arraste mostrou-se promissor para a redução da concentração de etanol em soluções hidroalcoólicas, podendo ser futuramente aplicado durante o processo fermentativo, a fim de contornar a inibição pelo etanol.

\section{AGRADECIMENTOS}


Os autores agradecem ao Programa de Recursos Humanos da Agência Nacional do Petróleo pela bolsa de iniciação científica concedida ao primeiro autor, à Coordenação de Aperfeiçoamento de Pessoal de Nível Superior - CAPES pela bolsa de doutorado concedida ao segundo autor e à Fundação de Amparo à Pesquisa do Estado de São Paulo (FAPESP) pelo apoio financeiro para desenvolvimento dos estudos (Processo FAPESP 2012/50046-4).

\section{REFERÊNCIAS}

BADINO, A.C.; CERRI, M.O.; HOKKA, C.O. Sistema reacional pneumático e uso do mesmo. Patente licenciada (PI0701608-5), 2007.

ESPERANÇA, M. N. Avaliação das transferências de calor e massa na recuperação de etanol por arraste de $\mathrm{CO}_{2}$. Trabalho de Graduação, Departamento de Engenharia Química, UFSCar, 2011.

MOTA, H. S. Análise técnico econômica de unidades geradoras de energia distribuída. Dissertação de Mestrado. Instituto de Pesquisas Energéticas e Nucleares, USP, 2011.

RODRIGUES, M.I., IEMMA, A.F. Planejamento de Experimentos e Otimização de Processos: Uma estratégia Sequencial de planejamentos. Casa do Pão Editora, 2005.

SONEGO, J. L. S., LEMOS, D. A., RODRIGUEZ, G. Y., CRUZ, A. J. G., BADINO, A. C., 2014. Extractive Batch Fermentation with $\mathrm{CO}_{2}$ Stripping for Ethanol Production in a Bubble Column Bioreactor: Experimental and Modeling. Energy \& Fuels, 28(12),p. 7552 - 75592014. 